WOMEN IN CANCER PROFILE

\title{
Neuroendocrine tumors: moving from the land of small tumors to an expanding universe
}

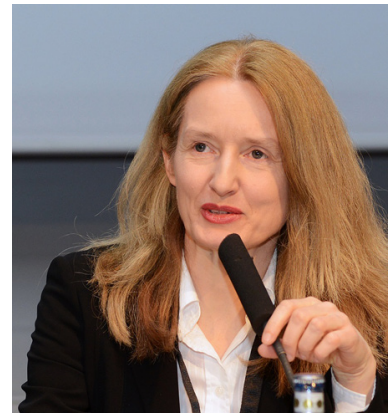

\section{Marianne E Pavel}

Medical Department, Division of Hepatology and Gastroenterology including Metabolic Diseases, Campus Virchow Klinikum, Charité Universitätsmedizin Berlin, Berlin, Germany

Correspondence should be addressed to M E Pavel

Email

marianne.pavel@charite.de
While growing up in a town near Hanover (Havelse) in Germany, my wish was to become a teacher. My passion for biochemistry as well as for arts and the French language grew during my high school years. By the end of high school, I began considering both molecular biology and art history in addition to languages for my future professional life. For this reason, I decided to study medicine in combination with the French language.

In autumn 1985, I started my medical studies as a major and minored in French at the Romanistic Institute at the Georg August University of Göttingen in Germany. There I achieved a natural science degree in French in 1987. Throughout my six years of medical education, I performed my practical training in departments of endocrinology at different hospitals in France including the University of Nice, Hopital de Cimiez and the University in Montpellier. Within the last year of my medical studies in Paris at the Pierre et Marie Curie University, I also undertook training in surgery. Enabled by substantive semester breaks, German medical students can undertake professional training in foreign countries for up to three months. In as much, I have considered myself lucky to have been able to combine my practical medical training and studies and still enjoy art and culture in France.

During my medical studies at the Georg August University of Göttingen in the late 1980s, I was truly inspired early by my mentor and University teacher Prof Dr med. h.c. Werner Creutzfeldt, FRCP to begin working in the field of neuroendocrine tumors. Prof Creutzfeldt, head of the Department of Gastroenterology and Endocrinology was a leader of excellence in the field of gastrointestinal endocrinology, neuroendocrine tumors and the entero-insulinar axis/incretin system in Germany, which paved the way for new treatment strategies in diabetes mellitus. While working on his ward at the Department of Gastroenterology and Endocrinology, I also worked with his expert team of physicians and researchers, which included at the time Fritz Stöckmann and Wolfgang Schmidt who conducted studies on circulating tachykinins related to flushing in carcinoid syndrome, and the effect of octreotide on secretion and symptom control, as well as studies on the expression and functional role of peptide hormones like pancreastatin and pituitary adenylate cyclase-activating polypeptide (PACAP) (Creutzfeldt \& Stöckmann 1987, Schmidt et al. 1989). This research encompassing basic sciences to clinical studies as well as the evaluation of therapeutic strategies combined with international connections to other NET groups impressed me very much, so I decided to stay further on in this field. In the last year of my practical training and medical studies in 1991/1992 on Prof Creuzfeldt's ward, I made my first contact with numerous patients who had distinct types of NET and had been referred from all over Germany. I was fascinated by the multiple facets of the disease that had been very well depicted in the article published by Charles Moertel - 'An odyssey in the land of small tumors' in 1987 (Moertel et al. 1987). At this time, treatment of NET, i.e. pancreatic NET was reduced to the use of chemotherapeutics like streptozotocin and others with less success. One of the great discoveries of this period was the introduction of

This paper is part of a special section on Celebrating Women in Cancer Research. The Guest Editors for this section were Charis Eng and Deborah Marsh.

Downloaded from Bioscientifica.com at 04/26/2023 09:43:08AM 
somatostatin analogs, particularly octreotide that inhibits gastroenteropancreatic secretion and tumor-related secretion of bioactive compounds (Balks et al. 1989) along with studies by Jean Claude Reubi on the expression and distribution of somatostatin receptors (sstr) by in situ hybridization (Reubi 1992). At the time of my training, there were no approved drugs available for NET, other than octreotide and interferon alpha for syndrome control. Clinical trials with SMS 201-995 (octreotide) were still ongoing in carcinoid syndrome as combination therapies of octreotide and interferon (Creutzfeldt et al. 1991).

Clinical trials in Germany and Sweden further explored the role of somatostatin analogs and interferon for tumor growth control. Prof Rudolf Arnold, a former alumnus of Werner Creutzfeldt, also inspired me by his exceptional view on tumor biology. He described the natural variability of tumor growth behavior including spontaneous growth arrests (Arnold et al. 2000), and initiated the first placebo-controlled trial (PROMID study, NCT00171873) worldwide on neuroendocrine tumors. This trial focused on midgut NET and demonstrated the antiproliferative efficacy of octreotide (Rinke et al. 2009). These results finally led to the approval of octreotide for antiproliferative purpose in most countries. This trial took a decade, due to the fact that most intestinal NETs have low proliferative activity (NET G1) and are slow growing. It took two decades to finally publish the overall survival data from this first small placebo-controlled trial (Rinke et al. 2016).

After medical studies, which coincided with the retirement of Werner Creutzfeldt, I took my first position as a fellow at the Friedrich Alexander University (FAU) of Erlangen Nuremberg, where I worked for 14 years. I specialized in Internal Medicine in 2000 and in Endocrinology and Diabetes in 2001. During this time, I co-founded the first patient support group for NET in Germany with Prof Johannes Hensen, former chief endocrinologist at the FAU Erlangen whom I have to thank for my endocrinology training. Within the Department of Gastroenterology, the NET center grew to one of the three largest centers in Germany. For many years, I was the editor of a patient journal (Glandula NET) that distributed knowledge about NET to all regions in Germany. In turn, the importance of education by offering training and lecturing on a local, national and international level had begun to play a big role in the course of my career. Through this endeavor, I was able to meet Prof Kjell Öberg from the Uppsala University, Sweden and hold lectures to this day at his Department, which was and still is a great pleasure. Thanks to him and Irvin Modlin,
Yale University, I was lucky to be a part of the Nordic Traveling Society group visiting several international and renowned institutions in Europe and the United States for some years, and this was also the basis for the establishment of scientific collaborations. Furthermore, I enjoyed teaching the training courses together with the pathologists Prof Günter Klöppel and Prof Martin Anlauf at the International Academy of Pathology in Bonn. Also, I became involved in the organization of national and international summer schools at the Charité in Berlin later on.

In May 2007, I was offered a position at the Department of Gastroenterology and Hepatology at the Charité Berlin by Prof Bertram Wiedenmann who dedicated his research to neuroendocrine tumors and co-founded the European Neuroendocrine Tumor Society (ENETS). He provided me a platform to further evolve in this field. In January 2010, I was appointed as Professor of Neuroendocrine Tumors by the Senate of Berlin and have been working in the field of NET exclusively since May 2007.

The NET center in Berlin was one of the first in Europe that was recognized as an accredited ENETS Center of Excellence (CoE) in 2009. One of my main tasks was to build a clinical trial center at the Charité. Here, I was involved in most of the recent international trials as a leading investigator. In 2015, a total of 15 prospective clinical drug trials related to NET were ongoing at the clinical trial center, which I implemented. I have always felt that it is of utmost importance to offer new drugs to my patients. In this regard, some of the paths that Charles Moertel had envisaged for NET 30 years ago, the NET community has pursued. Although the number of approved drugs is still limited in NET, I could not have imagined the advancements in therapy since the era of somatostatin analogs. Due to the rarity of the disease, large randomized controlled trials could only be initiated in an international setting involving 50-70 centers from different parts of the world. Since the introduction of somatostatin analogs and interferon alpha, it took more than two decades to achieve approval of novel drugs, among them novel targeted drugs to inhibit tumor growth. I was predominantly involved in the exploration of somatostatin analogs, particularly of lanreotide in the CLARINET study (NCT00353496) (Caplin et al. 2014) and of novel drugs in non-pancreatic NET, among them everolimus (RADIANT-2,NCT00412061; RADIANT-4,NCT01524783) (Pavel et al. 2011, Yao et al. 2016) that recently was approved by Food and Drug Administration (FDA) and European Medicines Agency (EMA) for therapy of

Published by Bioscientifica Ltd 
progressive non-functional NET of GI or lung origin. It is a great advancement to have the first drug approved for lung NET and to have options beyond SSA in GI NET. Further, next to Matthew Kulke's group at Dana Faber University, Boston, we first explored LX1606, an oral tryptophan hydroxylase inhibitor, in patients with refractory carcinoid syndrome (NCT00853047, NCT01104415), while on therapy with somatostatin analogs (Kulke et al. 2014, Pavel et al. 2015). These small phase II studies in patients with carcinoid syndrome fulfilled an unmet need in patients suffering from diarrhea related to serotonin hypersecretion. One of my patients moved from southern Germany to Berlin to have access to this trial. Based on the results of these trials, two phase III placebo-controlled trials, TELESTAR (NCT01677910) and TELECAST (NCT02063659), were initiated to further explore the efficacy of LX1606 (telotristat etiprate). The development of this drug can be considered a major achievement not only for syndrome control but also for the hope it provides to potentially delay the occurrence of carcinoid heart disease in patients with carcinoid syndrome.

I am not only concerned and interested in making novel drugs possible for patients but also interested in clinical research related to prognostic factors in NET including novel biomarkers to predict disease progression (Hilfenhaus et al. 2013, Pavel et al. 2016). One of my research projects supported by the DKTK (Deutsches Konsortium für Translationale Krebsforschung, German Cancer Foundation, Heidelberg) focuses on the evaluation of a mutational panel for prognostic purpose. The aim is to identify a molecular signature that distinguishes indolent tumors from more aggressive ones in the near future. In turn, this will allow patient stratification to a watch-and-wait strategy or to somatostatin analogs or alternatively to more aggressive therapies. Another project (DKTK Master), in collaboration with DKTK and the Comprehensive Cancer Center at the Charité (CCCC), aims to identify novel molecular targets for patients resistant to established therapies. The disease is rare and diverse, and as there are many more drugs that are currently explored in the field, it will not be feasible to investigate them all in clinical trials. Thus, I am interested in understanding the interaction of pathways in NET and a more molecularly driven personalized therapy. I am part of an international consortium guided by Prof Christine Sers, Department of Pathology at the Charité on a systems biology approach dealing with the MapTOR Kinase pathway in pancreatic NET supported by the BMBF - 'Bundesministerium für Bildung und Forschung'
(German Federal Ministry of Education and Research; http://www.sys-med.de/de/demonstratoren/maptor-net). This is a novel approach towards understanding how network behavior in the context of specific genetic alterations can have an influence on therapy.

Since 2005, I am involved in the activities of the ENETS, where I participate in consensus meetings for the construction of guidelines for diagnosis and therapy of NET and serve as lecturer and chair for many sessions during the annual conferences. In March 2014, I was appointed as a member of the ENETS Executive Committee and thank my international colleagues and friends for supporting me to accept this important appointment.

My profession is my passion, and it has allowed me to connect with physicians dealing with neuroendocrine tumors all over the globe. I especially have enjoyed visits from physicians from different countries at the Charité who have come to see how we manage NET. In this context, I have to mention that I have greatly appreciated working with my interdisciplinary team made up of experts from the various disciplines as well as physicians who have joined me for research projects.

Looking back now, I feel very grateful to have had the chance to plunge into a topic truly inspired by one of the leading physicians in Germany during my student times. In addition, I appreciated finding kind and strong support along my way at the different institutions where I have worked. They have allowed me to focus on a special disease that still leaves so many questions unanswered, but has, however, allowed me to gain insight, which is knowing that we are just in the beginning of a new era towards better understanding this heterogenous disease. There is still a long way to go. My mission is to stay tuned to neuroendocrine tumors.

\section{Declaration of interest}

The author declares that there is no conflict of interest that could be perceived as prejudicing the impartiality of this profile.

\section{Funding}

This work did not receive any specific grant from any funding agency in the public, commercial, or not-for-profit sector.

\section{Acknowledgements}

Faculty member and recipient of a research grant of the German Cancer Consortium (DKTK), Heidelberg, Germany. Bundesministerium für Bildung und Forschung (German Federal Ministry of Education and Research; http:// www.sys-med.de/de/demonstratoren/maptor-net); Az: 0101-31P9013).

Published by Bioscientifica Ltd 


\section{References}

Arnold R, Simon B \& Wied M 2000 Treatment of neuroendocrine GEP tumours with somatostatin analogues: a review. Digestion $\mathbf{6 2}$ (Supplement 1) 84-91. (doi:10.1159/000051861)

Balks HJ, Conlon JM, Creutzfeldt W \& Stöckmann F 1989 Effect of a long-acting somatostatin analogue (octreotide) on circulating tachykinins and the pentagastrin-induced carcinoid flush. European Journal of Clinical Pharmacology 36 133-137. (doi:10.1007/ BF00609184)

Caplin ME, Pavel M, Cwikla JB, Phan AT, Raderer M, Sedlackova E, Cadiot G, Wolin EM, Capdevila J, Wall L, et al. 2014 Lanreotide in metastatic enteropancreatic neuroendocrine tumors. New England Journal of Medicine 371 224-233. (doi:10.1056/ NEJMoa1316158)

Creutzfeldt W \& Stöckmann F 1987 Carcinoids and carcinoid syndrome. American Journal of Medicine 82 4-16. (doi:10.1016/00029343(87)90422-0)

Creutzfeldt W, Bartsch HH, Jacubaschke U \& Stöckmann F 1991 Treatment of gastrointestinal endocrine tumours with interferonalpha and octreotide. Acta Oncologica 30 529-535. (doi:10.3109/02841869109092413)

Hilfenhaus G, Göhrig A, Pape UF, Neumann T, Jann H, Zdunek D, Hess G, Stassen JM, Wiedenmann B, Detjen K, et al. 2013 Placental growth factor supports neuroendocrine tumor growth and predicts disease prognosis in patients. Endocrine-Related Cancer 20 305-319. (doi:10.1530/ERC-12-0223)

Kulke MH, O’Dorisio T, Phan A, Bergsland E, Law L, Banks P, Freiman J, Frazier K, Jackson J, Yao JC, et al. 2014 Telotristat etiprate, a novel serotonin synthesis inhibitor, in patients with carcinoid syndrome and diarrhea not adequately controlled by octreotide. EndocrineRelated Cancer 21 705-714. (doi:10.1530/ERC-14-0173)

Moertel CG 1987 Karnofsky memorial lecture. An odyssey in the land of small tumors. Journal of Clinical Oncology 5 1502-1522.

Pavel ME, Hainsworth JD, Baudin E, Peeters M, Hörsch D, Winkler RE, Klimovsky J, Lebwohl D, Jehl V, Wolin EM, et al. 2011 RADIANT-2 Study Group. Everolimus plus octreotide long-acting repeatable for the treatment of advanced neuroendocrine tumours associated with carcinoid syndrome (RADIANT-2): a randomised, placebo-controlled, phase 3 study. Lancet 378 2005-2012. (doi:10.1016/S01406736(11)61742-X)

Pavel M, Hörsch D, Caplin M, Ramage J, Seufferlein T, Valle J, Banks P, Lapuerta P, Sands A, Zambrowicz B, et al. 2015 Telotristat etiprate for carcinoid syndrome: a single-arm, multicenter trial. Journal of Clinical Endocrinology and Metabolism 100 1511-1519. (doi:10.1210/ jc.2014-2247)

Pavel M, Jann H, Prasad V, Drozdov I, Modlin IM \& Kidd M 2016 NET blood transcript analysis defines the crossing of the clinical Rubicon: when stable disease becomes progressive. Neuroendocrinology [in press]. (doi:10.1159/000446025)

Reubi JC 1992 Somatostatin receptors in the gastrointestinal tract in health and disease. Yale Journal of Biology and Medicine $\mathbf{6 5}$ 493-503.

Rinke A, Muller HH, Schade-Brittinger C, Klose KJ, Barth P, Wied M, Mayer C, Aminossadati B, Pape UF, Blaker M, et al. 2009 Placebocontrolled, double-blind, prospective, randomized study on the effect of octreotide LAR in the control of tumor growth in patients with metastatic neuroendocrine midgut tumors: a report from the PROMID Study Group. Journal of Clinical Oncology 27 4656-4663. (doi:10.1200/JCO.2009.22.8510)

Rinke A, Wittenberg M, Schade-Brittinger C, Aminossadati B, Ronicke E, Gress TM, Müller HH \& Arnold R PROMID Study Group 2016 Placebo controlled, double blind, prospective, randomized study on the effect of octreotide LAR in the control of tumor growth in patients with metastatic neuroendocrine midgut tumors (PROMID): results on long term survival. Neuroendocrinology [in press] (doi:10.1159/000443612)

Schmidt WE, Stöckmann F, Choudhury AR, Wilms HM, Siegel EG, Nustede R, Fölsch UR \& Creutzfeldt W 1989 Influence of CCK antagonist L-364,718, pancreastatin (33-49) and a somatostatin analogue on camostate-induced rat pancreatic hypertrophy. Digestion 44 105-116. (doi:10.1159/000199899)

Yao JC, Fazio N, Singh S, Buzzoni R, Carnaghi C, Wolin E, Tomasek J, Raderer M, Lahner H, Voi M, et al. 2016 RAD001 in Advanced Neuroendocrine Tumours, Fourth Trial (RADIANT-4) Study Group. Everolimus for the treatment of advanced, non-functional neuroendocrine tumours of the lung or gastrointestinal tract (RADIANT-4): a randomised, placebo-controlled, phase 3 study. Lancet 387 968-977. (doi:10.1016/S0140-6736(15)00817-X)

Received in final form 14 September 2016

Accepted 19 September 2016

Accepted Preprint published online 19 September 2016 (c) 2016 Society for Endocrinology Printed in Great Britain
Published by Bioscientifica Ltd. 